
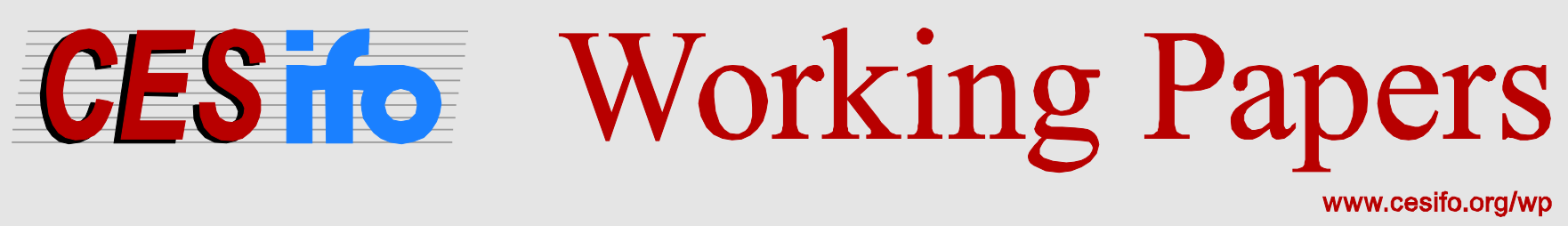

\title{
Trade with Endogenous Transportation Costs: The Value of LNG Exports
}

\author{
Atle Oglend \\ Petter Osmundsen \\ Tore Selland Kleppe
}

CESIFO WORKING PAPER NO. 5222

CATEgORY 8: TRAdE POLICY

FEBRUARY 2015

An electronic version of the paper may be downloaded

- from the SSRN website:

- from the RePEc website:

- from the CESifo website:

WwW.SSRN.com

www.RePEc.org

www.CESifo-group.org/wp 


\title{
Trade with Endogenous Transportation Costs: The Value of LNG Exports
}

\begin{abstract}
This paper investigates the economic value of trade when prices of transportation services are endogenous to cross-market price spreads. This is relevant for liquefied natural gas (LNG) exports. LNG transportation capacity is limited in the short-run, and long lead-times are involved in extending the transportation infrastructure. We establish empirically that LNG transportation costs have been endogenous to regional gas prices spreads. As such, transportation service providers have been able to capture part of the price spread. We proceed to develop a method to value LNG exports under conditions of endogenous transportation costs and market integration. We use this method to quantify the effect of endogenous transportation costs on the value of LNG exports from the US to Japan. Our analysis shows that when transportation costs are correctly treated as endogenous, the LNG export benefit can drop by as much as $20-50 \%$ relative to the case of exogenous cost.
\end{abstract}

JEL-Code: F130, Q270, Q480.

Keywords: LNG, natural gas, export, trade policy.

\author{
Atle Oglend* \\ Department of Industrial Economics \\ University of Stavanger / Norway \\ atle.oglend@uis.no
}

\author{
Petter Osmundsen \\ Department of Industrial Economics
University of Stavanger / Norway \\ Department of Industrial Economics
University of Stavanger / Norway \\ petter.osmundsen@uis.no
}

Tore Selland Kleppe

Department of Mathematics and

Natural Sciences

University of Stavanger / Norway

tore.kleppe@uis.no

*corresponding author

The authors would like to thank Jørn Bakkelund, Dag Tjøstheim and Hans Jarle Kind for valuable comments on the paper. 


\section{Introduction}

Changes in relative prices of commodities across different markets can signal new profitable trading strategies, and subsequently put pressure on policy makers to relax trade restrictions. While economic theory in general states that reducing trade barriers increases net economic benefits, the magnitude and distribution of these economic rents depends on the technological and economic constraints involved in transportation. When transportation is technologically demanding and requires large capital investments, the supply of transportation services is inelastic in the short run, and changes in demand for transportation services will lead to adjustments in prices of services. In such instances, some of the economic benefit of favorable trade conditions will accrue to transportation service providers. If these providers do not reside in, or tax to, the exporting economy, assuming fixed or exogenous transportation costs can lead to an overvaluation of export benefits. This is the novelty of our paper, an important point that seems to have been ignored in the discussion of Liquefied Natural Gas (LNG) exports from the US. In a recent report commissioned by the US Department of Energy, the US was projected to gain net economic benefits from allowing more LNG exports (Nera, 2012). The report concludes that increases in export revenues will more than offset the negative effects of higher natural gas prices for domestic gas users. The report, however, assumes no limits on LNG shipping capacity. Transportation cost is treated as exogenous, as in the economic literature on trade (Dixit and Norman, 1980). LNG freight capacity is limited in the short run as it comprises specialized transportation vessels with considerable lead-time in construction. As we will document, LNG transportation costs are not in general exogenous to relative gas prices. Our analysis suggests that endogenous transportation costs can reduce export benefits by as much as $20-50 \%$ conditional on the state of the market when exports are allowed. In addition, endogenous transportation costs will hurt flexible spot-trade more than fixed contractual trade. Exporters who do not have the flexibility to wait out unfavorable market conditions, for instance due to contractual obligations on delivery, will in periods of unfavorable net price spreads be less hurt by endogenous transportation costs relative to the case of exogenous transportation cost, since the periods of loss will be of shorter duration.

This paper makes three specific contributions. First, we investigate empirically the relationship between LNG freight rates and regional natural gas prices, providing empirical evidence that treating the LNG freight rate as exogenous to regional gas market conditions is, in general, not valid. The shale-gas expansion in the US and the Fukushima incident in Japan has led to large and persistent price spreads between natural gas in the US, Japan and Europe. These market conditions have clearly revealed the 
endogenous nature of LNG freight rates. In this period, both freight capacity utilization and freight rates have followed the development in relative prices. Our second contribution is to develop a simple method to value the economic benefits to exporters of having access to a new market when prices of transportation services are endogenous to the cross-market price spread. We highlight that endogenous transportation costs have a negative effect on export profitability, an effect that is equivalent to stronger cross market integration. With endogenous transportation costs, any emerging arbitrage opportunity will more quickly vanish as increased demand for transportation services drives up marginal transportation costs. Endogenous transportation costs reflect the technological barriers present in transporting commodities. With endogenous transportation costs it follows that cross-market price spreads can be persistently high without any arbitrage opportunity being present, leading to weaker price convergence between markets. This is our third contribution.

We use our method to analyze and quantify how endogenous transportation costs affect LNG export benefits from the US to Japan. This directly relates to policy decisions on whether to approve more export terminals of LNG from the US. Sempra and its partners in the Cameron LNG project have taken final investment decision to build the 12 million mt. p.a. facility in Hackberry, Louisiana. ${ }^{1}$ It is expected to start production by 2018 . This will be the third export facility built in the US. In addition, FERC gave Dominion LNG approval to build the Cove Point LNG export terminal on the Chesapeake Bay in Maryland, expected to go into service June 2017. The capacity of all four projects given FERC approval can potentially reach 57 million $\mathrm{mt}$. p.a.

The paper is organized as follows. The next section provides background on natural gas markets and trade, along with an empirical analysis of the relationship between natural gas price spreads and LNG freight rates. In section 3 we present a method to value export benefits under conditions of endogenous transportation cost and market integration. Section 4 investigates the method numerically based on different plausible market scenarios. We specify our numerical analysis to be representative of LNG exports from the US (Pacific North West and Gulf of Mexico) to Japan. We focus here on quantifying the effects of endogenous transportation costs on the export benefit. Finally, section 5 offers discussion of the results and concluding remarks.

\footnotetext{
${ }^{1}$ RS Platou, LNG shipping market, October 2014.
} 


\section{Background and Motivation: Natural Gas Trade}

There is an uneven distribution of natural resources around the world and substantial economic resources must be dedicated to transporting extracted resources and derived products between production regions and markets. For crude oil, transportation is relatively inexpensive, and one often speaks of a global pool of oil. Several papers have investigated the global economic impact and importance of oil (Kilian, 2009; Kilian and Murphy, 2014; Hamilton, 1983,2003). Compared to oil, natural gas is costly to transport in its natural state. Regional pipeline infrastructure is common, but ultimately limited in its geographical reach. Gas liquefaction technology allows the transformation of natural gas to a liquid state. The resulting higher energy density enables transportation over longer distances. However, the necessary infrastructure is costly. Liquefaction and regasification facilities must be in place in the exporting and importing regions, and specially built LNG carriers are necessary to transport the liquefied gas. The customized vessels require considerable lead times in procurement and construction. The high capital costs and limited shipping capacity pose substantial barriers for LNG in facilitating a fully global market for natural gas, akin to the global pool of oil. Yegorov and Dehnavi (2012) , for instance, discuss the presence of LNG arbitrage in recent years and find little support for large arbitrage opportunities because of high transportation costs. Despite limited arbitrage in periods of high capacity utilization, LNG has the potential to generate a more globally integrated market for gas (Li et al., 2014). Neumann (2012) and Li et al. (2014) provide some evidence that increased LNG trading to some extent has led to stronger spot price convergence.

In addition to issues in transportation, natural gas is traded differently around the world. In Japan in 2013, 73\% of LNG trades took place under long term contracts (LTCs) (Agerton, 2014). LTCs are considered desirable as they provide security of trade for buyers and sellers in a thin market, leading to lower financing costs for large and irreversible capital investments (Brito and Hartley, 2007; Hartley et al., 2013). Oil indexed LTCs are also common for gas trade in continental Europe. The oil indexation explains, in part, why gas prices in Europe are fully integrated with oil prices (Asche et al., 2001; Asche et al., 2002; Asche et al., 2006; Siliverstovs et al., 2005; Panagiotidis and Rutledge, 2007). In markets where spot trade is more prevalent and gas-to-gas competition stronger, such as the US, the relationship between oil and natural gas prices tend to be much weaker (Villar and Joutz, 2006; Parsons and Ramberg, 2012). In recent years, this has been reinforced by the US shale gas expansion (Kerr, 2010; Joskow, 2013). Excess supply from shale gas production has led to fully decoupled gas and oil prices in the US (Erdos, 2012; Oglend et al., 2016). 


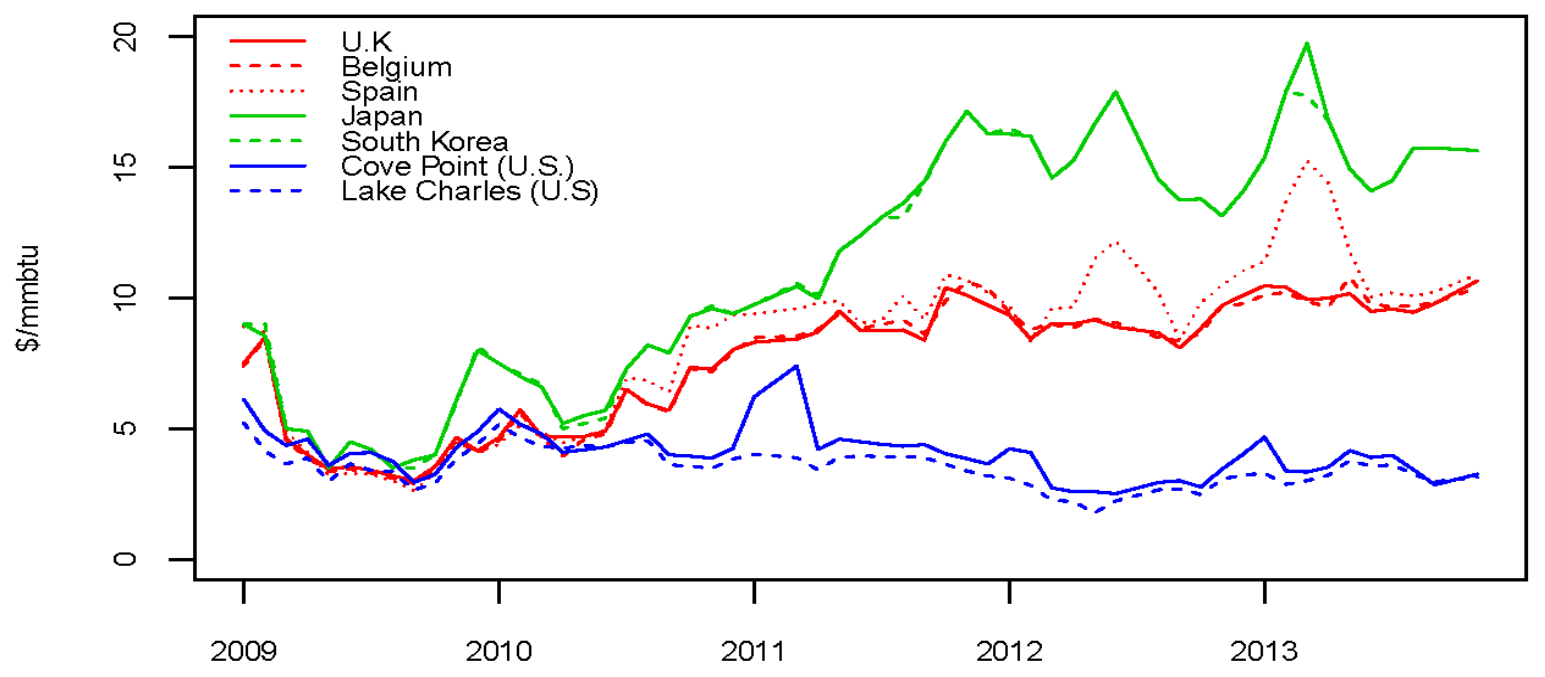

Figure 1. Regional natural gas (LNG) pricing in recent years. Data source: FERC.

Figure 1 highlights the differences in regional natural gas prices. The high spread after 2010/11 is largely due to shale gas in the US and the Fukushima incident in Japan. Economically viable extraction of shale gas provided a substantial, and largely unexpected, increase in the domestic availability of natural gas in the US. The lack of means to export the gas led to decoupling of domestic natural gas and oil prices in the US in 2009 (Erdos, 2012; Oglend et al., 2016), and later to diverging regional gas price spreads. At the same time, strong demand for LNG from Japan following the 2011 Fukushima incident helped support the high spreads. Market conditions thus suggest substantial economic benefits from US LNG exports, also after returns from investments in liquefaction facilities and LNG carriers are accounted for. 


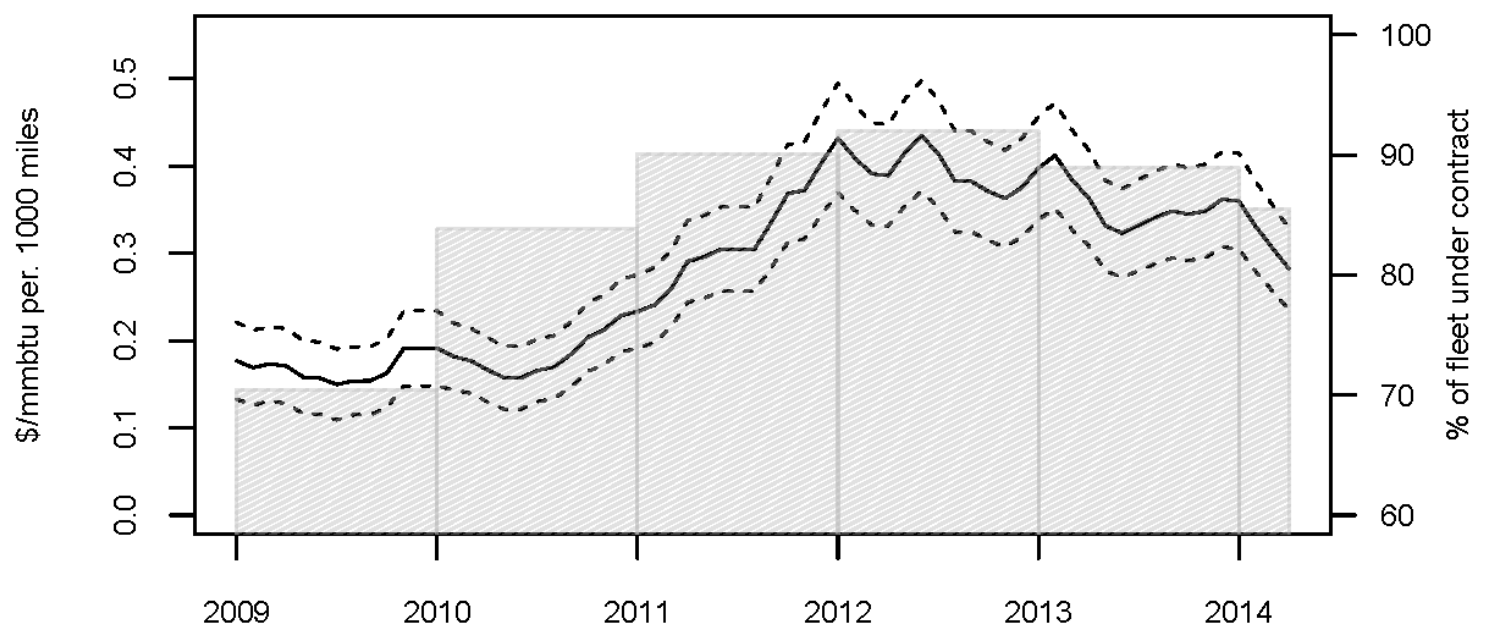

Figure 2. Freight rates and capacity utilization. Data source: Datastream and RS Platou

Figure 2 shows cross-sectional averages of 27 LNG freight rates representative of global LNG trade flows (data from Datastream). The dotted lines are +/- two standard deviations from the cross sectional averages. The figure also shows annual freight capacity utilization, defined as the share of the fleet under contract (www.platou.com). Two things are immediately clear from this figure. Freight rates have increased together with capacity utilization, suggesting inelastic supply of freight services. In addition, the period associated with high regional price spreads in figure 1 coincide with the periods of higher capacity utilization and higher freight rates. This suggests that inelastic freight supply in a period with increased demand for freight has pushed up freight rates. Subsequently, freight providers have captured some of the rent associated with the high cross-market price spreads, reducing the rent to cross-regional marketing.

\subsection{Empirical Analysis}

In this section, we provide a more detailed look at the empirical relationship between the representative freight rate in figure 2 and the Japan/US regional price spread. Our primary interest is to quantify the relationship between freight rates and the price spread. We start by considering the static relationship, before we look at dynamics. 
To investigate the static relationship we estimate a state-dependent linear regression between the Japan/US price spread and the freight rate. The relationship between the freight rate and the price spread likely depends on the state of freight capacity utilization. To accommodate this, we allow the linear relationship to change between two states. In this investigation we proxy the US gas price by the Henry Hub spot price and the Japan gas price by LNG import price (all data is publically available at http://data.worldbank.org/data-catalog/commodity-price-data). Since oil is relevant to the pricing of natural gas in Japan, we include the Brent oil price in the regression. Brent oil is generally considered the benchmark crude oil price. All data are monthly observations from January 2006 to May 2014. Prior to estimation, all variables were standardized to zero mean and unit standard deviation. In the state dependent regression, we allow the linear regression relationship to change between the equivalent linear regressions equations

$$
\begin{aligned}
& \text { spread }_{t}=\beta_{0,1}+\beta_{F, 1} \text { freightrate }_{t}+\beta_{O, 1} \text { oilprice }_{t}+\sigma_{1} u_{t}, \\
& \text { spread }_{t}=\beta_{0,2}+\beta_{F, 2} \text { freightrate }_{t}+\beta_{O, 2} \text { oilprice }_{t}+\sigma_{2} u_{t} .
\end{aligned}
$$

The probability of changing between the two states depends on fixed state transition probabilities. These are estimated jointly with the parameters in the linear regressions (see for instance Hamilton, 1989 for details around estimating the regime-switching model). Table 1 reports estimation results. The table also includes results from a simple linear regression (one state).

\begin{tabular}{|c|c|c|c|c|c|}
\hline \multicolumn{3}{|c|}{ Linear Regression Results (no state change) } & \multicolumn{3}{|c|}{ State Dependent Regression Results } \\
\hline & Coef. & S.E. & & Coef. & S.E. \\
\hline$\beta_{0}$ & - & - & $\beta_{0,0}$ & -1.085 & 0.345 \\
\hline$\beta_{F}$ & 0.807 & 0.159 & $\beta_{0,1}$ & 0.372 & 0.037 \\
\hline \multirow[t]{4}{*}{$\beta_{c}$} & 0.081 & 0.207 & $\beta_{F, 0}$ & 0.157 & 0.391 \\
\hline & & & $\beta_{F, 1}$ & 0.610 & 0.073 \\
\hline & & & $\beta_{O, 0}$ & 0.063 & 0.099 \\
\hline & & & $\beta_{O, 1}$ & -0.014 & 0.086 \\
\hline ADF & -2.43 & & & -5.206 & \\
\hline
\end{tabular}

TABLE 1. Estimation Results

Note: S.E. are heteroskedastic and autocorrelation consistent standard errors. ADF is the Augmented Dickey Fuller test statistics applied to the model residuals (null is unit-root, alternative is trend stationarity). 
The linear model results show a statistically significant positive relationship between freight rates and price spreads. The oil price is insignificant. However, the price spread and freight rates are all nonstationary over the sample ${ }^{2}$, and standard asymptotic inference is not applicable to derive parameter standard errors. In addition, the empirical residuals show evidence of non-stationarity, indicating the possibility of a spurious relationship.

There is clear evidence that the relationship between freight rats and price spreads have changed over the sample period. Standard linearity tests applied to the two-state models show strong rejection of linearity ${ }^{3}$. For the state-dependent model, the estimated transition probability matrix has an absorbing state. The state changed permanently in July 2008. This coincides with the start of the shale gas expansion in the US and the financial crisis. In the first state, freight rates have no statistically significant relationship with price spreads. In the latter period, a strong positive relationship is present. Accounting for the structural change ensures that residuals reject a unit root. This suggests that the freight rate and price spread share a common stochastic trend in the latter part of the sample. Figure 3 shows the freight rate and price spread. The grey shaded region differentiates the two pricing states.

\footnotetext{
${ }^{2}$ ADF test statistics are -2.696 (Japan/US spread), -2.694 (EU/US spread) and -2.056 (freight rate). Null hypothesis is unit-root, alternative is trend stationarity. 5\% (1\%) critical values are $-3.46(-4.06)$.

${ }^{3}$ Linearity LR-test Chi ${ }^{2}(5)=179.21$ ( $p$-value 0.0000) for the JPN-US Spread. Null hypothesis is linear relationship.
} 


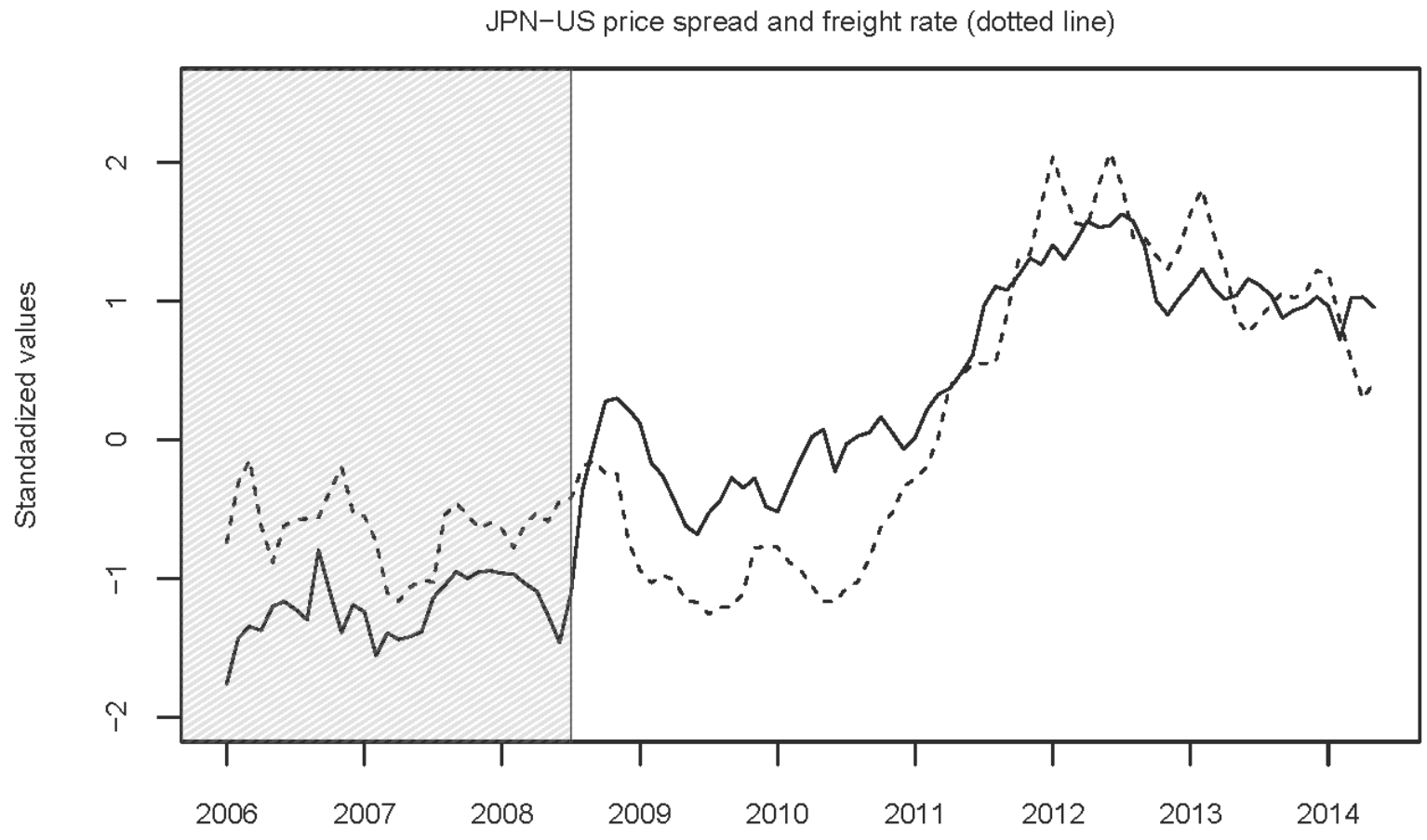

Figure 3. Standardized JPN-US gas price spreads (solid line) and freight rates (dotted line) over the two pricing states (shaded/non-shaded regions)

In the first state (shaded grey), spreads and freight rates were level and stable. In the latter state, freight rates and spreads share a common stochastic trend. This slow increase, leveling off and slight decline in price spread and freight rate is consistent with the movement in freight capacity utilization in figure 2.

As a final investigation, we estimate the joint dynamics of the data in the latter sample period using a vector error correction model (VECM). We estimate the following model for the joint dynamics of the standardized freight rates and price spreads

$$
\left[\begin{array}{c}
\Delta s_{t} \\
\Delta f r_{t}
\end{array}\right]=\left[\begin{array}{l}
\mu_{1} \\
\mu_{2}
\end{array}\right]+\left[\begin{array}{l}
\alpha_{1} \\
\alpha_{2}
\end{array}\right]\left[s_{t-1}-\beta f r_{t-1}\right]+\left[\begin{array}{ll}
\gamma_{11} & \gamma_{12} \\
\gamma_{21} & \gamma_{22}
\end{array}\right]\left[\begin{array}{c}
\Delta s_{t-1} \\
\Delta f r_{t-1}
\end{array}\right]+\left[\begin{array}{l}
\varepsilon_{1, t+1} \\
\varepsilon_{2, t+2}
\end{array}\right]
$$

Our main interest are the parameters $\alpha_{1}$ and $\alpha_{2,}$, measuring the adjustments to deviations from the implied long-run relationship, and the parameters $\gamma_{12}$ and $\gamma_{21}$, measuring short-run cross-dependence. If $\alpha_{2}<0$, the freight-rate adjusts to deviations from the long-run relationship, and if $\gamma_{21} \neq 0$ it adjusts to 
short-run movements in the price spread. The trace test for cointegration (Johansen, 1988) confirms the presence of a common stochastic trend ${ }^{4}$ from the static analysis.

TABLE 2. Estimation Output VECM

\begin{tabular}{cccc} 
& Coefficient & S.E. & p-value \\
\cline { 2 - 4 }$\alpha_{1}$ & -0.276 & 0.074 & 0.000 \\
$\alpha_{2}$ & 0.302 & 0.094 & 0.001 \\
$\gamma_{21}$ & -0.021 & 0.119 & 0.855 \\
$\gamma_{12}$ & -0.055 & 0.087 & 0.531 \\
$\beta$ & 0.632 & 0.033 & 0.000
\end{tabular}

Table 4 shows the estimation results on the coefficients of interest. Short-run cross-dependences are not statistically different from zero, but both the price spread and freight-rate adjust to deviations from the long-run relationship between the variables. The dynamic analysis here means that the freight rate is not exogenous - in a Granger causality sense - to the price spread, but will tend to increase and decrease when the spread increases or decreases. The response is quite strong in the part of the sample analyzed, a one standard deviation increase in the spread today leads to 0.28 standard deviation increase in the freight rate the following month.

Overall, the empirical analysis suggests that freight rates have not been exogenous to regional gas market conditions. In the next section, we use this to to quantify the effect of an endogenous transportation cost on LNG export benefits.

\section{The Export Premium under Endogenous Transportation Costs}

We want to determine the value to US LNG exporters of having access to the Japanese LNG market. We will refer to this value as the LNG export premium. We consider monthly export profits over a valuation horizon of $T$ months. The export premium gives the net present value (over what could be earned if the gas could only be marketed domestically) of having access to LNG exports to Japan over $T$ months following the month the export licenses become available.

\footnotetext{
${ }^{4}$ Hypothesis: Rank of cointegration matrix <= 0: Trace Statistic $=30.944$ ( $p$-value 0.000). Hypothesis: Rank of cointegration matrix $<=1$ : Trace Statistic $=1.0368$ ( $p$-value 0.309).
} 
The LNG export premium assumes exporters are free to commit to exports any given month, conditional on the observed state of the market: the price spread of natural gas between the US and Japan and the freight rate. If exports are committed, exporters capture the entire price spread, but must pay for the cost of liquefaction and transportation. Due to the long lead-times and the irreversible investment involved in establishing the LNG transportation infrastructure, much LNG trade currently takes place under long-term contracts. The specific details of these contracts and their dispersion across different exporters are not well known. We allow exporters to capture the entire net spread. Thus, the export premium is an upper bound on the value of LNG exports under a regime of flexible spot trade. Increased LNG spot trade is likely to encourage much greater volume and destination flexibility in LNG contracts than what has traditionally been the case for long term contracts (Hartley et al., 2013).

Suppose LNG exporters in the US can, at time $t$, purchase natural gas domestically at a price $p_{U S, t}$. Exporters pay for the liquefaction and subsequent transportation of LNG to Japanese regasification terminals. Let $\bar{c}_{L I Q}$ be the unit liquefaction cost. Furthermore, let $f_{t}$ be the standardized freight rate, and $\delta$ the total transportation distance in 1000 miles from the liquefaction plant in the US to the regasification plant in Japan. If exports are committed a month, exporters can secure a price $p_{J P N, t}$ for the LNG delivered in Japan.

Exporters will commit to shipments a month as long as it is profitable. The per unit export profit at time $t$ is

$$
\begin{aligned}
& \pi_{E X P, t}=S_{t}-C_{t}, \\
& C_{t}=\delta f_{t}+\bar{c}_{L I Q}, \\
& S_{t}=p_{J P N, t}-p_{U S, t},
\end{aligned}
$$

where $C_{t}$ is the unit marketing cost and $S_{t}$ the price spread. If $\pi_{E X P, t}<0$, exports will not be committed, and net profit is zero. With this decision criterion, the export profit a given month is

$$
\pi_{t}=\max \left\{\pi_{E X P, t}, 0\right\}=\max \left\{\left(S_{t}-C_{t}\right), 0\right\}
$$

With a valuation horizon of $T$ periods and a required rate of return of $r$, the LNG export premium is the expected discounted profits, per unit, from LNG exports over the valuation horizon

$$
\varpi\left(S_{0}, C_{0}\right)=\sum_{t=0}^{T} \frac{1}{(1+r)^{t}} E_{0} \pi_{t}
$$


where we set current time to zero. Expectations are taken with regards to the information available on the state of the market when exports become operational.

The export premium depends on both the current and expected state of the market. We formulate general reduced form equations for the state variables allowing us to capture both the effect of market integration and endogenous transportation costs on the export premium. Market integration implies that the cross-market price spread adjusts over time to the unit transportation cost of the lowest cost exporter, denoted here by $C_{t}$. Since transportation costs cannot be negative, while price spreads can, we model the joint dynamics of $S_{t}$ and the logarithm of the transportation cost, $c_{t}=\log \left(C_{t}\right)$. The state variables follow the stochastic processes

$$
\begin{aligned}
& \Delta S_{t}=k_{s}\left(S_{t-1}-C_{t-1}\right)+\varepsilon_{s, t}, \\
& \Delta c_{t}=k_{c, 1}\left(S_{t-1}-C_{t-1}\right)-k_{c, 2}\left(c_{t-1}-\bar{c}\right)+\varepsilon_{c, t}, \\
& {\left[\begin{array}{l}
\varepsilon_{s, t} \\
\varepsilon_{c, t}
\end{array}\right] \sim N(\mathbf{0}, \mathbf{\Omega}) .}
\end{aligned}
$$

In equation (6a), $k_{s}<0$ determines the degree of market integration. The degree of market integration will determine the persistence of arbitrage opportunities. Stronger market integration means the net price spread, $S_{t}-C_{t}$, closes more quickly. In the cost equation (6b), $k_{c, 1} \geq 0$ determines the rate at which the unit cost adjusts to the net price spread. A positive (negative) net spread means increasing (decreasing) demand for transportation services and subsequent changes in the price of services. When $k_{c, 1}=0$, the marketing cost is exogenous to the price spread. The quantity $\bar{c}$ represents the long run (log) marketing cost. Current (log) cost above (below) $\bar{c}$ is assumed to give rise to expansion (contraction) of available transportation capacity, and to subsequent changes in costs, at a rate determined by $k_{c, 2}>0$.

The export premium has a lower bound at zero. Having a new market available can never have a negative value to a single exporter. The exporter can always choose never to use the new market. When market integration increases, for instance due to more responsive entry/exit in the market, the spread will spend less time above and below the unit cost. With stronger market integration, the net spread adjusts more quickly to eliminate any profitable or unprofitable export conditions. A more responsive 
cost has an equivalent effect on export profits. The net spread will adjust more quickly to profitable or unprofitable export conditions. The total effect of increased market integration, or a more responsive cost, depends on the initial state of the market. If exports are currently unprofitable, $S<C$, the spread will tend to stay below $C$ for a shorter amount of time. The opposite occurs if the market is in a state of profitable exports, $S>C$. Arbitrage opportunities become less persistent, reducing export profitability. Since exporters can sit and wait out unfavorable market conditions, but commit when conditions are favorable, the export premium under flexible exports will decrease when market integration increases or transportation costs become more responsive to the spread.

\subsection{Numerical Analysis}

We use the procedures discussed above to quantify the effect of endogenous transportation costs on the value of LNG exports from the US to Japan. We are careful to note here that this is not a complete description of the full economic benefit of LNG exports. Our purpose is to investigate the sensitivity of export profits to endogenous transportation costs.

We will consider LNG shipments from two regions in the US, the Pacific North-West, represented by Astoria, and the Gulf of Mexico, represented by Sabine. Exporters in Astoria are assumed the lowest cost marketers of LNG from the US to Japan. The travel distance from Astoria to Japan is approximately 8400 nautical miles (round trip). The distance from Sabine is approximately 18200 nautical miles (round trip, Pacific route). We assume both regions have access to the same liquefaction technology, where liquefaction cost is set to $\$ 2 / \mathrm{mmbtu}$. Both regional exporters can charter freight at the same competitive rate, denoted in $\$ / \mathrm{mmbtu}$ per 1000 nautical miles. The LNG transportation cost $(\$ / \mathrm{mmbtu})$ from the Pacific North-West to Japan is $C_{t}=8.4$ freightrate $_{t}+2$. When calculating the cost from the Gulf to Japan, we set this at $40 \%$ above the cost from the Pacific North-West. Using a mean freight rate of $\$ 0.25$, the equilibrium transportation cost from the Pacific North-west is $\$ 4.11 / \mathrm{mmbtu}$. The required rate of return on the exports is set to $10 \%$ annually.

The export benefit is investigated under different scenarios for the degree of market integration and responsiveness of costs to the price spread. The full list of the different scenarios is given in table 3 . Outside the parameters listed in the table, we set the degree of mean reversion in the cost, $k_{c 2}$, to a fixed value of -0.03 for all scenarios. This is quite low, reflecting the low elasticity of supply of transportation services in the short-run. The standard deviation of shocks are calibrated to give 
unconditional standard deviations of the spread and cost equal to $\$ 3.5 / \mathrm{mmbtu}$ and $\$ 1.75 / \mathrm{mmbtu}$ respectively. These represent historical values, and the fact that the spread has been significantly more volatile than freight rates.

TABLE 3. Different LNG marketing scenarios

\begin{tabular}{|c|c|c|}
\hline Scenario: & Relevant parameters: & Note: \\
\hline $\begin{array}{l}\text { Low market } \\
\text { integration }\end{array}$ & $k_{s}=-0.01, k_{c 1}=0.01$ & $\begin{array}{l}\text { Doubling the spread from its equilibrium value it } \\
\text { will be reduced by } 50 \% \text { in } 60 \text { months }\end{array}$ \\
\hline $\begin{array}{l}\text { Medium market } \\
\text { integration }\end{array}$ & $k_{s}=-0.05, k_{c 1}=0.01$ & $\begin{array}{l}\text { Doubling the spread from its equilibrium value it } \\
\text { will be reduced by } 50 \% \text { in } 20 \text { months }\end{array}$ \\
\hline High market integration & $k_{s}=-0.10, k_{c 1}=0.01$ & $\begin{array}{l}\text { Doubling the spread from its equilibrium value it } \\
\text { will be reduced by } 50 \% \text { in } 10 \text { months }\end{array}$ \\
\hline $\begin{array}{l}\text { Exogenous } \\
\text { transportation costs }\end{array}$ & $k_{s}=-0.05, k_{c 1}=0.00$ & Unresponsive transportation cost \\
\hline $\begin{array}{l}\text { Intermediate cost } \\
\text { responsiveness }\end{array}$ & $k_{s}=-0.05, k_{c 1}=0.01$ & $\begin{array}{l}\text { Doubling the spread from its equilibrium value, } \\
\text { transportation cost will peak at } 42 \% \text { above its } \\
\text { equilibrium value in } 27 \text { months before it starts } \\
\text { decreasing }\end{array}$ \\
\hline $\begin{array}{l}\text { High cost } \\
\text { responsiveness }\end{array}$ & $k_{s}=-0.05, k_{c 1}=0.03$ & $\begin{array}{l}\text { Doubling the spread from its equilibrium value, } \\
\text { transportation cost will peak at } 71 \% \text { above its } \\
\text { equilibrium value in } 16 \text { months before it starts } \\
\text { decreasing }\end{array}$ \\
\hline
\end{tabular}

Figure 3 below shows simulated price spreads and transportation costs over 200 periods. These are derived using the stochastic processes in equations (6a) and (6b) under the scenario of exogenous transportation costs (red lines) and intermediate transportation cost responsiveness (blue line). The bottom panel shows the unit export profits for each period (equation (4)). We observe how endogenous transportation costs lead the cost to increase and decrease as the spread increases or decreases. Since the spread also adjusts to the cost, the prices spread moves differently in the two scenarios. Specifically, the spread is higher over time when costs are endogenous. Endogenous transportation cost leads to a more persistent spread with higher autocorrelation. The consequence is that regional gas markets appear less integrated. This highlights the barrier that limited capacity and technologically demanding transportation poses to creating integrated markets. 
Simulated price spreads and transportation costs with endogenous (blue) and exogenous (red) transportation costs

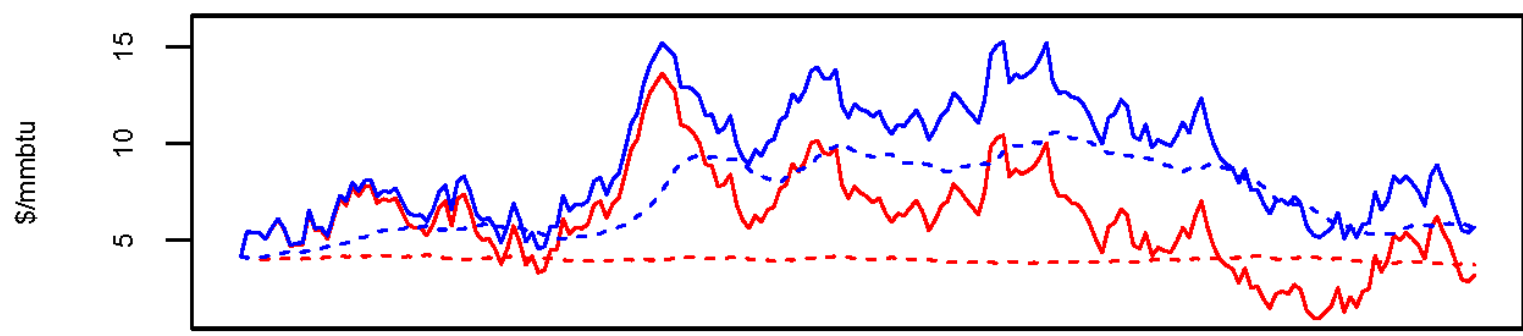

Monthly unit profit

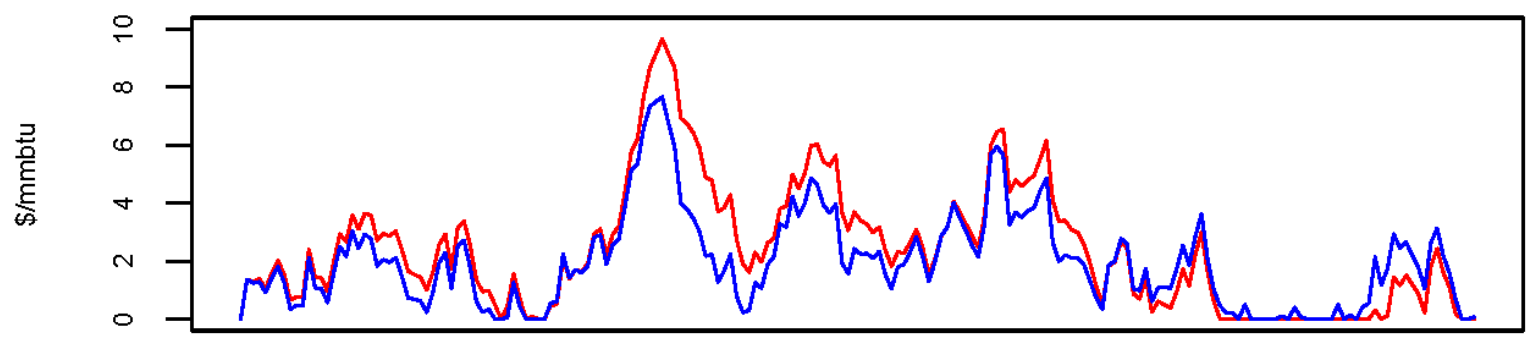

Figure 3. Simulated prices (solid lines top) and unit transportation costs (dotted lines, top) when transportation costs are exogenous (red) and endogenous (blue). Bottom panel shows unit export profits for each period.

The monthly unit export profit (bottom panel) is in general higher when costs are exogenous. However, this is not true for all states over the market. When the price spread is increasing and high, the responsive cost will reduce export profits. When the spread starts declining (as it does towards the end of the sample), the endogenous transportation cost also declines. When exports becomes unprofitable towards the end of the sample, the responsive cost is beneficiary to profitability since it will also decline. Over the entire sample, the sum of profits is $22 \%$ higher when costs are exogenous. The adjustment benefit of endogenous costs when exports are unprofitable is limited since exporters will in general choose not to export in these states in either scenario.

Table 4 reports the means and standard deviations of monthly unit export profits (equation (4)) over the different scenarios in table 3, and for exports from the Pacific North-West and the Gulf of Mexico. The means and standard deviations are derived by simulating 100,000 periods of spreads and cost. These are unconditional values with the initial state of the market when exports become available integrated out. We see from the table that when market integration increases, or the responsiveness of costs increases, 
the unconditional mean and standard deviation of monthly export profits fall. In addition, export profits from the Gulf are substantially below the lowest cost marketer for all scenarios. Direct unit costs are $40 \%$ higher for exports from the Gulf, but the mean profits are much lower than what is implied by the direct cost difference. The reason for this is that the higher unit cost not only reduces profits when transportation takes place, but substantially reduces the likelihood that any exports at all will be committed a given month. In addition, we do not consider the quantity difference in exports between the two regions. As shipping time from the north-west is lower, the monthly export capacity is higher with associated higher total profits if the capacity is fully utilized.

Table 4. Monthly Unit Export Profits $(\$ / \mathrm{mmbtu})$ over the different scenarios

\begin{tabular}{|c|c|c|c|c|c|}
\hline & & \multicolumn{2}{|c|}{ Lowest cost marketer (Pacific N.W.) } & \multicolumn{2}{|c|}{ Gulf of Mexico } \\
\hline & & $\begin{array}{l}\text { Mean Export } \\
\text { Profit }\end{array}$ & Std. Export Profit & $\begin{array}{c}\text { Mean Export } \\
\text { Profit }\end{array}$ & Std. Export Profit \\
\hline \multicolumn{6}{|c|}{ Market integration $\left(k_{s}\right)$ : } \\
\hline-0.01 & Low & 1.59 & 1.87 & 0.13 & 0.46 \\
\hline-0.05 & Medium & 0.81 & 1.12 & 0.11 & 0.38 \\
\hline-0.1 & High & 0.61 & 0.87 & 0.07 & 0.28 \\
\hline \multicolumn{6}{|c|}{ Cost endogeneity $\left(k_{1, c}\right)$} \\
\hline 0.00 & None & 0.99 & 1.41 & 0.37 & 0.85 \\
\hline 0.01 & Medium & 0.81 & 1.12 & 0.11 & 0.38 \\
\hline 0.03 & High & 0.63 & 0.81 & 0.05 & 0.25 \\
\hline
\end{tabular}

The value of export operations will depend on the state of the market when exports become operational. We now turn to investigate the effect of endogenous transportation costs on the LNG export premium over different initial states of the market. We assume that the valuation horizon for an LNG export operation is twenty years following the initial period. Starting at a given state $S_{0}$ and $C_{0}$, we simulate 10000 twenty year periods of spread and cost developments. For each of the 10000 twenty year periods we calculate the LNG export premium using equation (5). Figure 4 shows the LNG export premiums as a function of the initial price spread. For the blue lines, the initial transportation cost is low $(\$ 2.5 / \mathrm{mmbtu})$, the green line shows intermediate starting cost $(\$ 6.25 / \mathrm{mmbtu})$, while the red line is for high initial transportation costs $(\$ 10 / \mathrm{mmbtu})$. Panel (a) shows the export premium in the exogenous cost scenario, panel (b) the intermediate cost responsiveness scenario and panel (c) the high cost responsiveness scenario. These are from the point of view of the lowest cost exporter, the Pacific northwest to Japan. 
For all scenarios and initial transportation costs, the export premium is convex and increasing in the initial spread. The convexity is due to the lower utilization of exports option at low price spreads. At high price spreads, any further increase in the spread is realized in immediate profit sas exports are not zero. At low initial spreads, no export takes places when it becomes available, and the premium increases in the spread only because the likelihood of future profitable exports increases. Both the level and slope of the export premium is lower when transportation costs adjust to the price spread. With a responsive cost, an increase in the spread is followed by an increase in the unit cost, reducing the unit export profitability. The absolute effect of endogenous transportation cost is greatest when licensed at a time when exports are profitable. When the spread is low and immediate exports less profitable, the endogenous transportation cost will reduce the length of the unprofitable period. This will counteract the negative effect of endogenous transportation costs over the full valuation horizon.

When exports are currently profitable, the premium is highest for all scenarios when it starts at a state of low initial transportation costs (blue lines). However, when spreads are low and exports unprofitable, the premium will increase in the transportation cost. This effect is due to the relative strength between market integration, adjusting the price spread, and the endogenous cost, adjusting the unit cost.

(a)

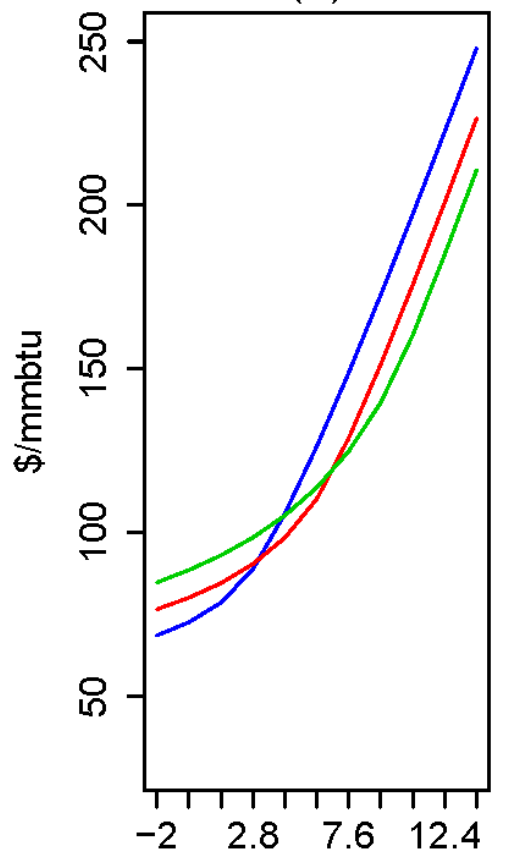

Price Spread $(\$ / \mathrm{mmbtu})$ (b)

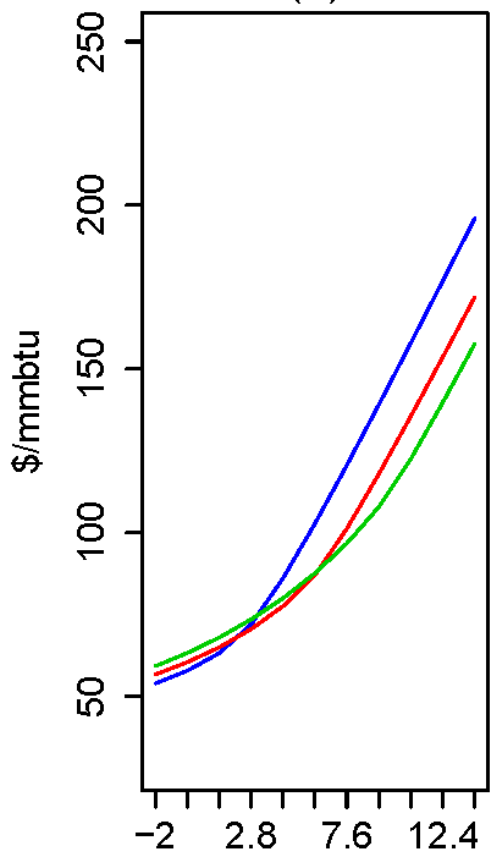

Price Spread $(\$ / \mathrm{mmbtu})$ (c)

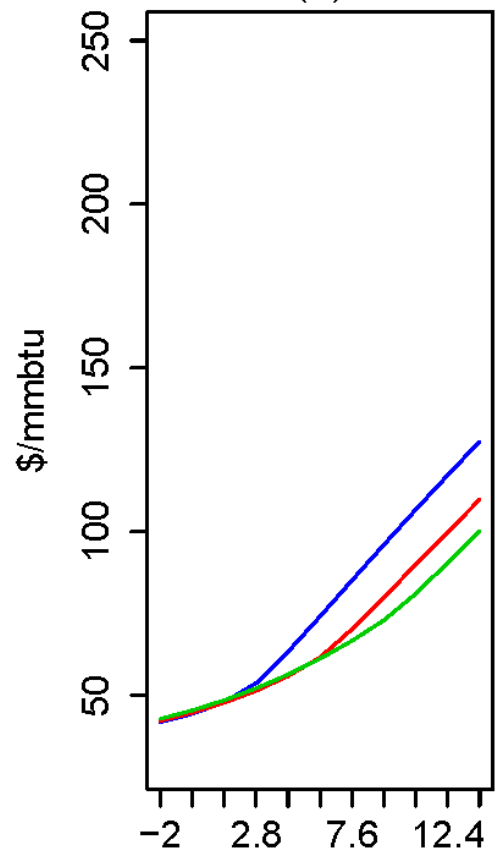

Price Spread (\$/mmbtu) 
Figure 4. The LNG Export Premium as a function of initial cross-market price spreads under (a) exogenous transportation costs, (b) intermediate cost responsiveness and (c) high cost responsiveness. Blue line starts at low transportation cost, green at intermediate transportation cost and red line at high initial transportation cost.

When the cost is very high relative to the spread (green line at low spreads), the price spread is pushed up (export relative to domestic price) as exports decline in response to the very unprofitable export conditions. If the cost is not as high relative to the spread (blue line at low spreads), there is weaker reduction in exports and the spread will consequently not increase as much. A strong upward adjustment in the spread due to strong market integration at high transportation cost explains why the premium increases in transportation costs when exports are not currently profitable. This effect weakens when costs become endogenous. In these scenarios, the cost itself will decline when it is high relative to the spread, reducing the subsequent upward movements in the spread. Intuitively, if the cost itself is expected to decline in response to unfavorable export conditions, there is less incentive to exit the market in response to currently unfavorable conditions - market conditions are expected to improve in the future. Consequentially, the price spread will not adjust as strongly upward as it would if transportation costs did not adjust.
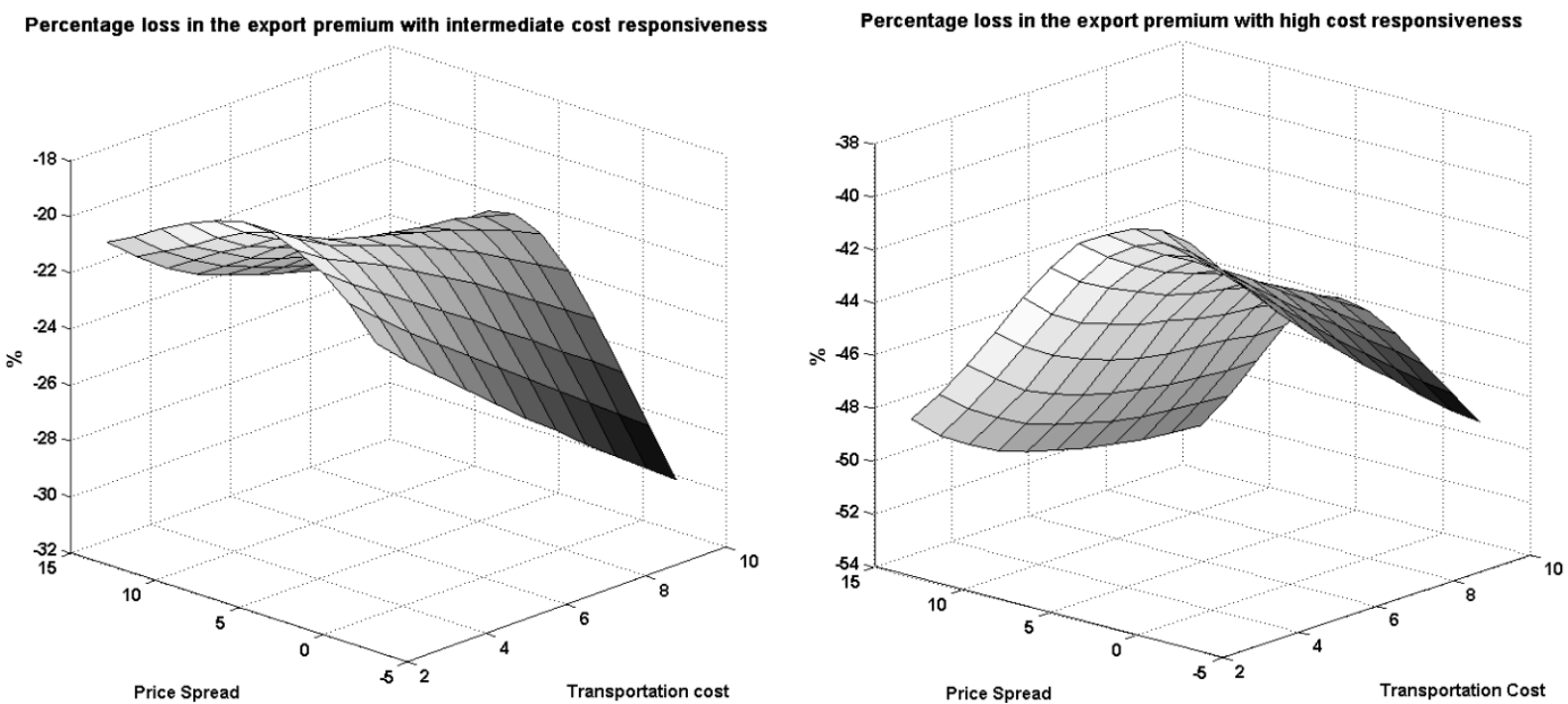

Figure 5. The relative effect of endogenous transportation cost on the LNG export premium, conditional on state of the market when exports become operational 
In figure 5, we show the average percentage loss in the LNG export premium relative to the exogenous transportation cost scenario over different initial states of the market. The left panel is loss under intermediate cost adjustment, the right under high cost adjustment. For the intermediate case, the export premium falls by between $20-30 \%$, conditional on the initial state of the market. With high cost responsiveness, the relative loss is between $40-50 \%$. The relative loss is lowest if the export option becomes available when costs do not currently deviate substantially from the spread, when the market is in short-run equilibrium with few profitable export options. As the spread deviates from the unit transportation cost, the relative loss in the export premium increases. The numbers here show that the effect of a responsive cost is non-trivial on the value of exports to exporters. Exporters can hedge against this loss by exposing some of their financial positions to LNG transportation services, either directly by owning LNG carriers or by allocating financial assets to companies providing freight services.

\section{Conclusion and Discussion}

When evaluating the value of a new market to an exporter, the economic benefit depends on whether we can treat marginal transportation costs as exogenous to marketing conditions. If marginal transportation costs respond to trade profitability, for instance due to low elasticity of supply of transportation services, they become endogenous. This is relevant for the global trade of liquefied natural gas, where transportation capacity is limited in the short-run and long lead-times are involved in extending the transportation infrastructure. The recent high price spreads between the US, Japan and European regional gas markets provides an experimental setting to test the endogeneity of LNG transportation costs. Using data on 27 LNG freight rates representative of global LNG trade flow, we show that freight rates do indeed move with the cross-market price spreads. We show that the movement in freight rates is consistent with the degree of freight-capacity utilization, as measured by the percentage of the LNG fleet under contract. Using a vector error correction model we document that from around 2008, the freight rates share a common stochastic trend with the Japan/US price spread, and that both the spread and freight rates adjust to deviations from this stochastic trend.

To investigate the economic value of exports under endogenous transportation cost, we formulate general reduced form equations for the joint dynamics of the cross-market price spread and unit transportation cost. These equations allow us to investigate the export value under different scenarios for both the degree of market integration and the responsiveness of transportation costs to export profitability. Stronger market integration and more responsive transportation cost have the same 
qualitative effect on export profitability. They both reduce the persistence of arbitrage opportunities and reduce the length of periods under which exports are unprofitable. In a state of increasing and high price spreads, endogenous transportation costs reduce export profits because the marginal transportation cost will increase to close the spread. When spreads are declining and low, transportation costs tend to decline, reducing the length of the periods of unprofitable exports. When exporters can wait out unfavorable market conditions (the periods when an endogenous transportation cost is favorable), endogenous transportation costs reduce mean export profits. A consequence of this is that exporters who do not have the flexibility to wait out unfavorable market conditions, for instance due to contractual obligations on delivery, will in periods of unfavorable net price spreads be less hurt by endogenous transportation costs relative to the case of exogenous transportation cost, since the periods of loss will be of shorter duration.

To investigate the sensitivity of export benefits to the timing of export licenses we calculate the LNG export premium under different initial states of the market and degrees of cost responsiveness to export profitability. The export premium summarizes the discounted expected economic flow of profits accruing to exporters of having access to exports to Japan relative to domestic marketing only, per unit of the commodity. This assumes exporters can capture the entire cross-market prices spread, but must pay for liquefaction and freight. For scenarios of intermediate and high transportation cost adjustment to export profitability, the LNG export premium falls by $20-50 \%$ percent relative to the case of exogenous transportation cost. The relative reduction is greatest if exports are available when the cross-market price spread deviates substantially from the unit transportation cost. If exports licenses are available when the spread is close to the unit-transportation cost, the negative relative effect of endogenous transportation cost on the export premium is minimized.

Our analysis has focused on the value of a new market to exporters, and as such does not consider the full economic effects of relaxing trade restrictions to an exporting economy. One additional factor is the location of suppliers of transportation services. If they are located in the exporting economy, the higher rents accruing to them from higher transportation costs will flow back to the economy. In a global freight market, it is however likely that a substantial share of the rent will flow out of the economy. The fact that freight rates have increased in line with higher price spreads between the US and Japan in recent years, means that some of the economic benefit of exports is likely to be diverted from exporters to transportation service providers. Thus, from a socio economic perspective, the timing of issuing new 
export licenses is crucial. Exporters can protect themselves against the loss caused by adjustment in transportation service prices by exposing some of their financial positions to LNG transportation services, either directly by owning LNG carriers or by allocating financial assets to companies providing freight services.

To what degree the transportation cost responds to price spreads will depend on the degree of capacity utilization, as illustrated in recent years. Capacity utilization of the LNG fleet was as high as 92 per cent in 2012 , with a resulting short-term rate of $\$ 125,000$ per day. According to RS Platou, we are now approaching a cyclical low, estimated at $\$ 58,000$ per day in $2015 .{ }^{5}$ The rates are not expected to go back to the 2012 level - 18 new carriers were delivered in 2014 and two carriers were removed from the market. In 2014, 28 new orders for LNG carriers have been reported. Thus, the timing of the existing LNG export licenses seems favorable. From a more general perspective, keeping in mind the endogeneity of freight rates, a continuation of the policy of gradual introduction of natural gas exports is recommended.

\section{References}

Agerton, M. 2014. "Global LNG Pricing Terms and Revisions: An Empirical Analysis."

Asche, F., P. Osmundsen, and M. Sandsmark. 2006. "The UK market for natural gas, oil and electricity: are the prices decoupled?" The Energy Journal:27-40.

Asche, F., P. Osmundsen, and R. Tveteras. 2001. "Market integration for natural gas in Europe." International Journal of Global Energy Issues no. 16 (4):300-12.

Asche, F., P. Osmundsen, and R. Tveterås. 2002. "European market integration for gas? Volume flexibility and political risk." Energy Economics no. 24 (3):249-265.

Brito, D.L., and P.R. Hartley. 2007. "Expectations and the evolving world gas market." The Energy Journal:1-24.

Dixit, A., and V. Norman. 1980. Theory of international trade: A dual, general equilibrium approach: Cambridge University Press.

Erdos, P. 2012. "Have oil and gas prices got separated?" Energy Policy.

Hamilton, J.D. 1983. "Oil and the macroeconomy since World War II." The Journal of Political Economy:228-248.

Hamilton, J.D. 2003. "What is an oil shock?" Journal of econometrics no. 113 (2):363-398.

\footnotetext{
${ }^{5}$ RS Platou, LNG shipping market update, october 2014.
} 
Hartley, P.R., P.R. Hartley, G. Mitchell, C. Mitchell, and J.A. Baker. 2013. The Future of Long-Term LNG Contracts: University of Western Australia, Business School, Economics.

Johansen, S.o.r. 1988. "Statistical analysis of cointegration vectors." Journal of economic dynamics and control no. $12(2): 231-254$.

Joskow, P.L. 2013. "Natural gas: from shortages to abundance in the United States." The American Economic Review no. 103 (3):338-343.

Kerr, R.A. 2010. "Natural gas from shale bursts onto the scene." Science no. 328 (5986):1624-1626.

Kilian, L. 2009. "Not all oil price shocks are alike: Disentangling demand and supply shocks in the crude oil market." The American Economic Review:1053-1069.

Kilian, L., and D.P. Murphy. 2014. "The role of inventories and speculative trading in the global market for crude oil." Journal of Applied Econometrics no. 29 (3):454-478.

Li, R., R. Joyeux, and R.D. Ripple. 2014. "International Natural Gas Market Integration." Energy Journal no. 35 (4).

Nera. 2012. "Macroeconomic Impacts of LNG Exports from the United States."

Neumann, A. 2012. "Linking Natural Gas Markets-Is LNG Doing its Job?" The Energy Journal no. 30 (Special Issue):187-200.

Oglend, A., Lindback, M, and P. Osmundsen (2016), "Shale Gas Boom Affecting the Relationship Between LPG and Oil Prices", Energy Journal, forthcoming, Vol 37, No. 1, 211-232.

Panagiotidis, T., and E. Rutledge. 2007. "Oil and gas markets in the UK: Evidence from a cointegrating approach." Energy Economics no. 29 (2):329-347.

Parsons, D.J., and J.E. Ramberg. 2012. "The Weak Tie Between Natural Gas and Oil Prices." The Energy Journal no. 33 (2).

Siliverstovs, B., g.G. L'H\'e, A. Neumann, and C. Von Hirschhausen. 2005. "International market integration for natural gas? A cointegration analysis of prices in Europe, North America and Japan." Energy Economics no. 27 (4):603-615.

Villar, J.A., and F.L. Joutz. 2006. "The relationship between crude oil and natural gas prices." EIA manuscript, October.

Yegorov, Y., and J. Dehnavi. 2012. "Is LNG Arbitrage Possible in Natural Gas Market?". 


\section{Appendix A}

Table A1. Distances from ports used when calculating standardized freight rates (numbers in miles)

\begin{tabular}{lllllllllll}
\hline \multirow{2}{*}{ From } & $\begin{array}{l}\text { To } \\
\text { South- } \\
\text { Korea }\end{array}$ & Japan & Altamira & Barcelona & Belgium & $\begin{array}{l}\text { Cove } \\
\text { Point }\end{array}$ & India & $\begin{array}{l}\text { Isle of } \\
\text { Grain }\end{array}$ & $\begin{array}{l}\text { Lake } \\
\text { Charles }\end{array}$ \\
\cline { 2 - 10 } & 6458 & 6006 & 9922 & 5165 & 6277 & 9445 & 1263 & 6249 & \\
Algeria & 9020 & 9491 & 5196 & 589 & 1778 & 3774 & 4421 & 1696 & 5117 \\
Australia & 3586 & 3518 & - & 7616 & 9307 & & 3857 & 9225 & 11749 \\
Nigeria & 10466 & 10695 & - & - & - & - & - & 4337 & 5256 \\
\hline
\end{tabular}

